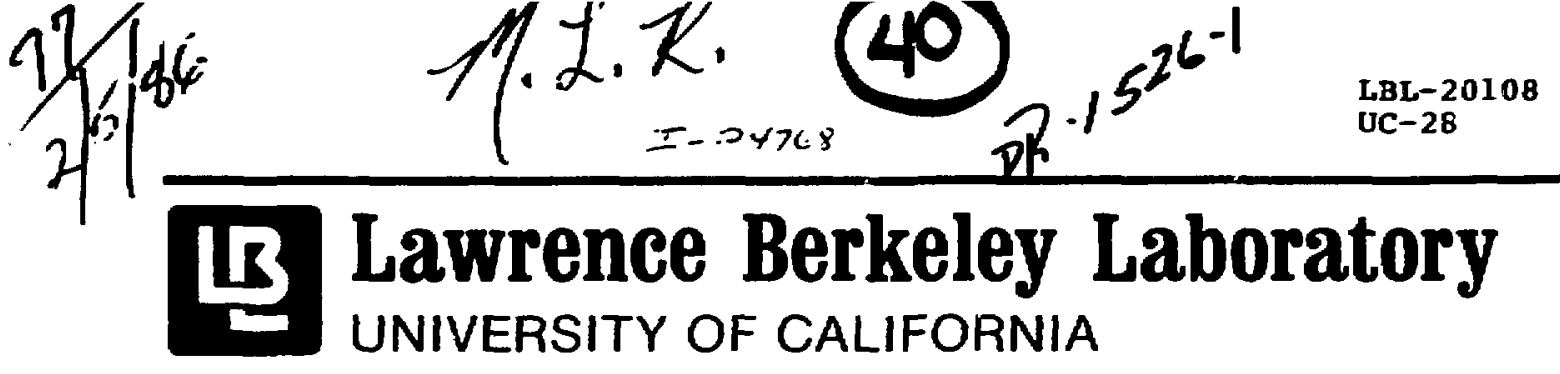
Facilities Management \&
LBL--20108
Technical Services Division
DE86 005850

NEUTRON DOSE EQUIVALENT AT ELECTRCN STORAGE RINGS

W.P. Swanson

August 1985

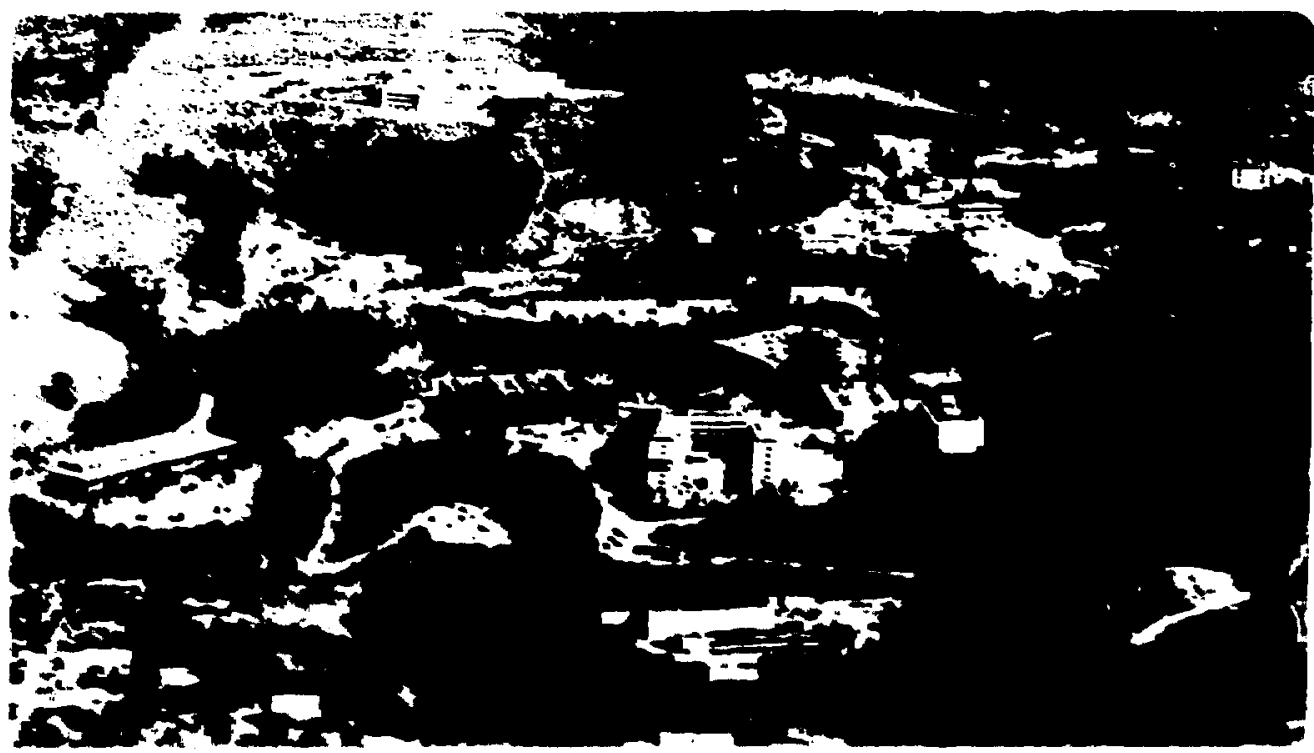




\title{
Neutron Dose Equivalent at Blectron Storage Rings
}

\author{
Milliam P. Swanson \\ Lawrence Berkeley Laboratory \\ University of California \\ Berkeley, California 94720
}

In the energy regime within which most electron storage rings operate (a few hundred $\mathrm{MeV}$ to tens of $\mathrm{GeV}$ ), the potentially harmful radiation is primarily caused by two sources: bremsstrahlung when the circulating beam is los from orbit, end giant-resonance photoneutrons produced in the resulting electrcmagnetic cascade. Of these, the bremsstrahlung dose is harder to treat analyti ally, owing to its forward-peaked angular distribution. However, it is shown below that the neutron dose equivalent can be predicted simply and with sufficient accuracy that radiation shielding can be designed with reasonable confldence.

\section{Ring Parameters Assumed}

The following parameters correspond to those anticipated for an existing electron storage ring, Aladdin, constructed at the Physical Sciences Laboratory of the University of Wiseonsin at Madison (Row81, Sym84):

$\begin{array}{lll}E_{0}= & 1 \mathrm{GeV} & \text { Energy of the circulating electrons } \\ I= & 1 \mathrm{~A} & \text { Average current } \\ \mathrm{R}_{0}= & 14.5 \mathrm{~m} & \text { Average radius of the ring* } \\ \mathrm{f}= & 3.3 \mathrm{MHz} & \text { Rotation frequency of the beam }\end{array}$

The above parameters are equ:valent to a stored energy of

$$
\mathbf{N}=298 \mathrm{~J} \text {. }
$$


In the picture developed below one imagines this amount of energy stored in the beam and subsequently lost in the stainless-steel vacuum pipe. The neutron fluence and dose equivalent calculated then correspond to one complete cycle of "store and dump".

\section{Neutron Source Term and D-E Conversion Factor}

The production of photoneutrons in electromagnetic cascades initiated by electrons has been calculated by Swanson (Swa78, Swa79a) and the resulting yields have been largely confirmed by measurement [see Table 2 of Swa78, Ste83, Yan84]. An important observation is that, for the energy range relevant to this report, the yield of neutrons from a given material is proportional to electron beam power, for any $\mathrm{E}_{0}$ above about twice the energy of the giant-resonance peak. The calculations of Swa79a for Fe for $\mathrm{E}_{0}=1 \mathrm{GeV}$ give

$$
\mathrm{Y}(\mathrm{Fe})=8.18 \times 10^{8} \text { neutrons } \mathrm{J}^{-1} \text {. }
$$

where the unit " $\mathrm{J}$ " refer to the total amount of energy, $W$, carried by the incident electron beam onto a thick sample of the material. For comparison, the yields from $\mathrm{Al}, \mathrm{Cu}$ and $\mathrm{Pb}$ are:

$$
\begin{aligned}
& Y(\mathrm{Al})=6.20 \times 10^{8} \text { neutrons } \mathrm{J}^{-1} \text {, and } \\
& Y(\mathrm{Cu})=11.8 \times 10^{8} \text { neutrons } \mathrm{J}^{-1} \\
& \mathrm{Y}(\mathrm{Pb})=21.3 \times 10^{8} \text { neutrons } \mathrm{J}^{-1}
\end{aligned}
$$

which represent differences of $-24 \%,+44 \%$ and $+160 \%$ from $Y(\mathrm{Fe})$ at $1 \mathrm{GeV}$, respectively. The photoneutron yield for Fe drops from its value at $1 \mathrm{GeV}$ by only $7 \%$ at $E_{0}=100 \mathrm{MeV}$. Iron is used in the present example because of the presence of a stainless-steel vacuum pipe and magnet yokes; the other materials $(\mathrm{N}, \mathrm{Cu}$, $\mathrm{Pb}$ ), because of their common usage, serve for comparison. Aluminum can be considered representative of concrele $[A=27$ for $\mathrm{Al}$, as compared to an effective atomic rumber $A_{\mathbf{z}} \approx 21$ for concrete]. If another material than $F e$ is used, the results can be appropriately scaled.

The total neutron yieid from a beam dump into irun is. then:

$$
\begin{aligned}
\mathbf{Q}=8.18 \times 10^{8} & =8.18 \times 10^{8} \times 288 \mathrm{~J} \\
& =2.36 \times 10^{11} \text { [neutrons perdump] }
\end{aligned}
$$


For conversion from neutron tuence to dose equivalent, we adopt the values from ICRP-21 (ICR73, Table 4). The spectrum of photoneutrons from the ciant photoneutron resonance resembles that of a fission spectrum (Swa79b, pp. 71-75) and the average energy varies relatively little with the atomic number of the medium in which the electromagnetic cascade occurs. For the present calculation, an average neutron energy of $2 \mathrm{MeV}$ is assumed. The corresponding conversion factor from ICRP-21 is:

$$
\begin{aligned}
& 7.0 \text { neutrons } \mathrm{cm}^{-2} \mathrm{~s}^{-1} \text { per mrem } \mathrm{h}^{-1} \\
= & 2.52 \times 10^{8} \text { neutrons } \mathrm{m}^{-2} \mathrm{mrem}^{-1}
\end{aligned}
$$

\section{Dose Equivalent at Ring Center}

The dose equivalent at ring center is particularly simple to calculate and, in many cases, easily accessible to measurement. Furthermore, its value is insensitive to the actual deviations from a uniform beam loss around the ring. The neutron fluence at a distance d from a point electron loss in an Fe medium is:

$$
\phi=\frac{Q}{4 \pi d^{2}}\left[\text { neutrons } \mathrm{m}^{-2}\right]
$$

As the center is equidistant from every point of the ring, we obtain for the neutron fluence at the ring center $\left(d=R_{0}\right)$ :

$$
\begin{aligned}
\phi_{c} & =Q /\left[4 \pi R_{0}^{2}\right]=\frac{8.18 \times 10^{8} \times 288 \mathrm{~J}}{4 \pi(14.5 \mathrm{~m})^{2}} \\
& =8.92 \times 10^{7}\left[\text { neutrons } \mathrm{m}^{-2}\right]
\end{aligned}
$$

Utilizing the above conversion factor. we obtain

$$
H_{c}=\frac{8.92 \times 10^{7} \text { neutrons } m^{-2}}{2.52 \times 10^{6} \text { neutrons } m^{-2} m^{-1}}=0.354 \mathrm{mrem} \text {. }
$$

for the neutron dose equivalent at the ring center.

\section{Dome Bquiveleat in the Itoding Fane}

The neutron dose equivalent at any point in the plane of the ring (median plene) is easily obtinined (rom equations $(2-4)$ by substituting the average value of the inverse-squared-distance from uniform circular source (see Appendix 1 ) $\operatorname{lor} \mathrm{d}^{\mathrm{Q}}$ : 


$$
\left.\widehat{\frac{1}{d^{2}}}\right\rangle=\left|\frac{1}{R^{2}-R_{0}^{2}}\right|=\left|\frac{1}{\left(R+R_{0}\right) S}\right|
$$

where $R$ is the distance from the ring center to the point in question and $S=\mid R$ $R_{0} l$. For $R \approx R_{0}$ we may use the approximation

$$
\left(\frac{1}{d^{2}}\right) \approx\left|\frac{1}{2 R_{0} s}\right|
$$

Substituting values of $\overline{d^{-2}}$ obtained from equation $(5)$ for a range of distances, $S$, leads directly to the values shown in Fig. 1. The neutron dose equivalent is plotted as a function of distance, $\mathrm{S}$, measured radially from any point on the ring, both inwards (towards the ring center) and outwards. The most general interpretation of these ring curves is that, for an arbitrary (non-uniform) beam loss distribution, they give the neutron dose equivalent averaged around arıy circle concentric with the electron ring. If uniform beam loss is assumed, these curves show the actual (unaveraged) values at the indicated distances from the ring.

For comparison, Fig. 1 also shows the neutron dose equivalent as a function of distance from a hypothetical infinite line source having the same strength as the ring in terms of neutrons per unit lengih. This curve has a strict $S^{-1}$ behavior.

As expected, the values for both ring curves of Fig. 1 merge and very closely approach the behavior of the infinite line source for small values of the distance, S. In fact, as equation (5) predicts, both ring curves obey an inverse-distance (not. inverse square) law for $S$ small compared to the ring radius. At a distance about equal to the ring radius, the dose equivalent deviates noticeably from a pure inverse-distance behavior; the curve inside the ring is at minimum, as symmetry would require. As one proceeds outward from the ring by the same amount, $S \approx R_{0}$. the dose equivalent has deviated from a pure inverse-distance law by about $34 \%$ and. then continues to roll over to become ncar!y inverse spuare for jistances greater than several tinues $R_{0}$. This can be seen by comperison with the uppermost curve of Fig. I which shows the neutron dose equivalent for a point-loss of the entire stored bearm at distance S. Comparison st the curve wilh the ring curves cleariy shows the relationship between the

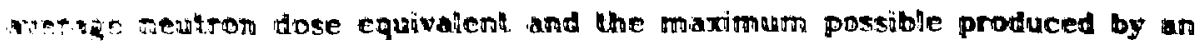

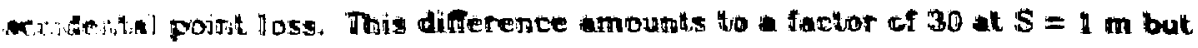


diminishes rapidly with $S$. Not coincidentally, the curve for point loss intersects precisely with the value at the ring center.

\section{Neutron Dose Bquivalent After Concrete Shielding}

Figure 2 shows the neutron dose equivalent in the median plane at $1 \mathrm{~m}$ from the ring assuming various thicknesses of intervening concrete. These results are computed by the summation of small increments $\left(\Delta \theta=1^{\circ}\right)$ around the ring. assuming uniform beam loss on the circumference. The geometrical model assumes that the inner surface of the concrete wall is contiguous with the ring. Each contribution is attenuated by its proper attenuation in the concrete, using a tenth-value layer of TVL $=92 . \mathrm{g} \mathrm{cml}^{-2}$ (Fas84). For a concrete density of $2.35 \mathrm{~g}$ $\mathrm{cm}^{-2}$, this corresponds to $39.2 \mathrm{~cm}$.

It is evident from Fig. $Z$ that there is a change in slope in the effective attenuation coefficient. This occurs because the first shielding layers strongly diminish the contributions of sources farther removed from the point of measurement, because of their larger slant ranges through the shielding. Thereafter the proximal arc source is attenuated in a manner which more resembles the attenuation of a point source of neutrons.

\section{Circumferential Distribution of Dose-Equivalent Contributions}

Figure 3 shows the curcumferential distribution of dose contributions to point $P$ at distance $S=1 \mathrm{~m}$ outside the ring, for chosen shielding thicknesses. Units are mrem $J^{-1}$, and the abscissa scale is such that $\theta=0$ when the source is closest to $P$. The meaning of this graph is that a point loss of $W$ Joules, anywhere around the ring (angle $\theta$ ), will contribute $n$ dose at point $P$ of the amount read on the ordinate scale. For an extended beam loss, one must integrate over theta, and that is what has been done in the preceding section, with the assumption of a uniformly distributed loss.

For no shielding, the dose at $P$ is dominated by a single large peak. symmetrical about $1=0$. As shielding is added (lower curves of Fig. 3). one sees that the peak itself is attenuated by some factor. depending on the shielding thickness, and contributions from across the ring $\left(\theta=180^{\circ}\right)$ are attenuated by approximately the same factor, whereas contributions near $=20^{\circ}$ ere severely altenualed, owing to thei: :erge slant distances through the shielding. All curves are symmelrical about $b^{\prime}$, as one would expect from the assumed isotropy of the source. 


\section{Accuracy}

To the extent that the photoneutron source can be considered a uniform isotropic ring source, and is unperturbed by such external influences as shielding, room scattering, or neutron multiplication by materials near the ring, the major uncertainties in the results of Figs. 1 and 2 are estimated as follows:

$\begin{array}{ll}\text { Uncertainty in neutron yield for Fe } & \pm 20 \% \\ \text { Uncertainty in correct value } & \\ \text { of DE-conversion factor } & \pm 15 \% \\ \text { Error resulting if the major } & \\ \text { neutron producing medium } & \\ \text { is not pure Fe, but rather } & \pm 29 \% \\ \text { a combination of Cu, Fe } & \\ \text { and Al (concrete) } & \pm 38 \%\end{array}$

For the arguments and results presented here to be valid. it must be assumed that the cascade is contained within the material of the vacuum pipe itself or in shielding material in close proximity; The case in which the electrons are dumped into a thin-walled pipe so that the electromagnetic cascade continues out into the room to produce photoneutrons in far-off corners would considerably lower and flatten the curves of Fig. 1.

In most cases the beam is not lost uniformly from orbit, but losses are concentrated in regions of high dispersion or of maximum amplitude in the betatron oscillations; more neutron shielding would be needed in such regions. However. the maximum needed anywhere should not exceed an amount determined by the uppermost curve of Fig. 1 for a point loss of the stored beam.

Possible shielding by objects near the beam line (especially magmets i is not considered here. Iron magnets are not good ubsorbers of giant-resonance neutrons, and their major effect would be to: iscalter the neutron fuences ïnuadent E.: them. As a fist approximation for radiation-prolection phanuing their shielding efreak, curs te considered as neutral. Another eftect. which can shignificanthy

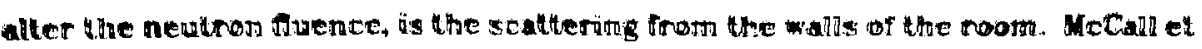

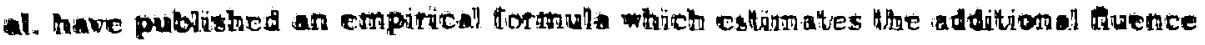


due to fast neutrnns scattered around a concrete room of area $A$ ( $A$ is the total for foor, ceiling and 4 walis combined) containing a neutron source of strength $Q$ neutrons (McCrY; also see Eis82):

$$
\phi_{\text {scat }}=5.4 \frac{Q}{A}
$$

As an example, assume the area of the room to be 20 times the area of the ring: $A$ $=20 \times \pi R_{0}^{2}=13210 \mathrm{~m}^{2}$. This would lead to a rather uniform coitribution of scattered fast neutrons of:

$$
\frac{\phi_{\text {scat }}}{\phi_{c}}=\frac{5.4 Q /\left[20 \pi R_{0}^{2}\right]}{Q /\left[4 \pi R_{0}^{2}\right]}=1.08
$$

relative to the fluence of direct neutrons at the ring center, $\phi_{c}$. This would therefore approximately double any measurement obtained at the ring center and add about $15 \%$ to the fluence measured at $1 \mathrm{~m}$ from the ring (inside or out). This contribution (approximate) is indicated as the horizontal line in Fig. 1.

\section{Implications for Radiation Protection}

For purposes of discussion, the arbitrary reference distarıe of $1 \mathrm{~m}$ from the ring is chosen to assess the radiation protection needs.

(1) The bremsstrahlung dose equivalent far exceeds the average neutron dose equivalent and will dominate the shielding (SwaEs). It is very probable that an adequate shield for bremsstrahlung will be more than adequate for the neutrons if concrete is used. However, if bremsstrahlung is shielded primarily by non-hydrogeneous materials such as $\mathrm{Pb}$ or $\mathrm{Fe}$, the neutrons may not be adequately attenuated.

(2) In itself, the unshielded neutron dose equjvalent is marginal; if one cycle of "store and dump" is executed ten times each 40-hour work week, the ICRP limit equivalent to $100 \mathrm{mrem} /$ week would be just reached (at $1 \mathrm{~m}$ ). However, in their Guidance on Maintaining Fxposures to As Low as Reasorably Achievable, the U. S. Department of Energy (DOF) states as a design objeclive: "... Onsite personnel levels less than one-fiftio of the permissible ... linnilts ... " (DOEB I). Therefore, at least some concrete shieldang is advisable

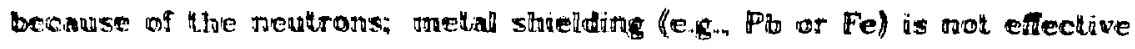

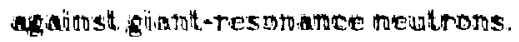


(3) At the site boundary (assume $50 \mathrm{~m}$ ) the direct neutron dose equivalent is less than the value at $1 \mathrm{~m}$ by a factor of 200, not taking into account any difference in elevation. At 1000 cycles of "store and dump" (fills) per year this would be:

$$
[0.020 \text { mrem } / \mathrm{fill}] \times[1000 \mathrm{fills} / \text { year }]=20 \mathrm{mrem} / \text { year }
$$

direct neutron dose equivalent with no neutron shielding. This is to be compared with the proposed revision of DOE radiation standards for protection of the public which "... incorporate a provision for Headquarters concurrence for anticipated routine operations that may result in estimated exposures exceeding $25 \mathrm{mrem} /$ year to any member of the public" (DOE84). This requircment appears to be satisfied even without shielding, as far as the neutron dose is concerned. An adequate shield against bremsstrahlung which contains at least some concrete would greatly improve upon this.

(4) These predictions are for the average neutron dose equivalent; regions of the ring where higher beam losses are expected should have increased shielding.

(5) The maximum possible accident is easily estimated from the point-loss prediction shown by the uppermost curve of Fig. 1.

\section{Applicability to other Isotropic Ring Sources}

The manner of scaling to the paranieters of other electron rings or circular accelerators (synchrotron, betatron) is quite obvious from the above equations $(2-5)$. It is implicit that ons shouid scale by the total stored beam energy, $W$. Loosely speaking, the neutron dose equivalent "near the ring" is proportional to $W / R_{0}$ and inversely proportional to $S$; if the ring radius, $R_{0}$, is not too different from $14.5 \mathrm{~m}$, one can scale the results of Fig. 1 approximately by the inverse radius [equation (6)]. For points not too far from the ring (i. e., less than half of $R_{0}$, one can scale as the inverse jistance, $S$, and for large distances (several times $R_{0}$ ) inverse square would be appropriate. Direct use of equation (5j) is almost as easy as the approximate scaling.

The Jnethond outumed above can be ad apled, willo appropriate modicications

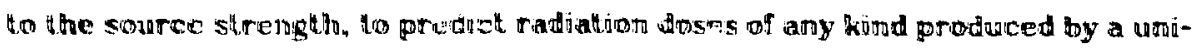

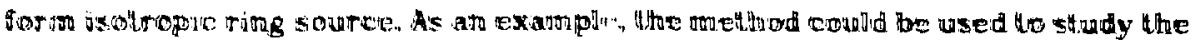

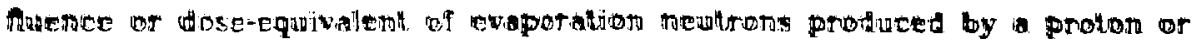
hearytion accelerallor. 


\section{Acknowledgements}

The author wishes to express his gratitude to the following persons for their support and encouragement during the course of this work: Klaus H. Berkner, Director of the LBL Accelerator and Fusion Research Division, Ralph H. Thomas. Deputy for Occupational Health, Jensen Young, Head of the LBL Environmerital Health and Safety Division and Joseph B. McCaslin, Head of the LBL Health Phy.* sics Section. I am also grateful to colleagues who worked on the Aladdin upgrade shielding study, for their untiring efforts in helping me to understand the radiation fields at Aladdin: Paul M. Deluca, Roger A. Otte, Robert T. Pedley and Steven W. Schilthelm, all of the University of Wisconsin Synchrotron Radiation Center. The support and encouragement of Professor Keith R. Symon, Director of the Synchrotron Radiation Center, was essential to this project and is warmly appreciated. 


\section{REFERENCES}

LOE81 U. S. Department of Energy, 1981, Guidance on Maintaining Exposures to As Low as Reasonably Achievable, Order No. DOE 5480.1, Chg. 6, pp. XI-13, 14 (13 Aug., 1981, Washington, D. C.).

DOE84 U. S. Department of Energy, 1984, Proposed revision of DOE Order 5480.1A, Radiation Standards for the Prolection of the Public, Ref. PE243 (17 Sept., 1984, Washington, D. C.).

Fis82 Eisenhauer, C. M., Schwartz, R. B. and Jobnson, T., 1982, Measurement of neutrons reflected from the surfaces of a calibration room," Health Physics 42, 489.

ICR73 International Commission on Radiological Protection, 1973, Data for Protection Against Ionizing Radiation from External Sources: Supplement to ICRP Publication 15, Report ICRP-21 (Pergamon Press, 0xford).

McC79 McCall, R. C., Jenkins, T. M. and Shore, R. A., 1979, Trensport of accelerator produced neutrons in a concrete room, IEEE Trans. Nucl. Sci. NS-26, 1593.

Row81 Rowe, E. M., Green, M. A., Hicks, J. W., Trzeciak, W. S. and Winter, W. R., Jr., 1981, Status of the Aladdin project. IEEE Trans. Nucl. Sci. NS-2B, 3145.

Ste83 Stevenson. G. R., Fassò. A., Höfert, M., Nielsen. M.C. and Rafinsøe , R. C., (1983). The yield of resonance neutrons from a thick copper target bombarded by electrons wilh energies up to $100 \mathrm{GeV}$, Nucl. Instrum. Melhods 216. 39.

Swa78 Swanson, W. P. 1978. Calculation of neutron yields released by electrons incident on selected malerials. Heath Physics 35.353.

Swi 79a Swanson, W. P., 1979a, Improved calculation of photoneutron yields released by incident electrons, Health Physics 37.347.

Swatgo Swanson. W. P. 1979b. Radiological Safely Aspects of the Dperation of

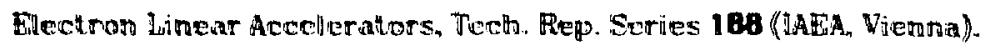

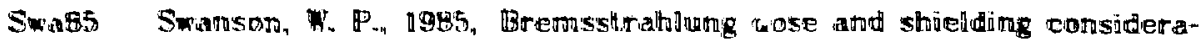

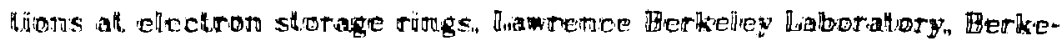
Dey, ch, in preparalion. 
Sym84 Symon, K. R., 1984, Physical Sciences Laboratory, U. Wisc.. Madison, private communication.

Yan84 Yang Yin, Li Yuxiong, Deluca, P. M., Jr., Otte, R. A. and Rowe, E. M., 1984, Neutron field measurement at the Aladdis Synchrotron Light Source. University of Wisconsin, to be published in Health Physics. 
Fig. 1 Neutron dose equivalent in the median plane as a function of distance. $S$, from an unshielded electron ring of radius $R_{0}=14.5 \mathrm{~m}$. Upper heavy curve: inwards towards ring center; Lower heavy curve: outwards from ring. Dose equivalents from a point source (for the same total number of electrons stopped) and $i_{-}-$an infinite line source (for the same number of electrons lost per unit length as for the ring) are also shown. Dashed line indicates approyinate contribution from scattered fast neutrons. Energy lost by dumped beam is $288 \mathrm{~J}$, correspondiıg to $1.8 \because 10^{12}$ electrons at $1 \mathrm{GeV}$, circulating at $3.3 \mathrm{MHz}(\mathrm{I}=1 \mathrm{~A})$.

Fig. 2. Neutron dose equivalent in the median plane, at $\mathrm{S}=1 \mathrm{~m}$ from the ring. as a function of conurete thickness. Ring and beam parameters are same as for previous figure. Density of concrete assumed is $2.35 \mathrm{~g} \mathrm{~cm}^{-3}$. Dashed line illustrates slope corresponding to TVL $=39 \mathrm{~cm}$ (arbitrary normalization).

Fig. 3. Neutron dose equivalent at $S=1 \mathrm{~m}$ from ring, per $\mathrm{J}$ lost at any point on the ring circumference, as a function of angle subtended at ring center. $\mathrm{R}_{0}=14.5 \mathrm{~m}$. Curves are labeled to show $0.0,0.1$ and $0.5 \mathrm{~m}$ of concrete shieldirug. 


\section{APPENDIX l: Average inverse distance-squared from a ring source.}

Imagine a point of observation, $P$, at distance $R$ from the origin, $O$, and a source point, $Q$, on the periphery of a circle of radius $R_{0}$ centered at $O$. The angle between $O P$ and $O Q$ is $\theta$ and the distance $Q P$ is called $d$. For every choice of $R_{1} R_{0}$ and $\theta$, the law of cosines gives:

$$
d^{2}=\left[R^{2}+R_{0}^{2}-2 R R_{0} \cos \theta\right]=a+b \cos \theta .
$$

where $a=R^{2}+R_{0}^{2}$ and $b=-2 R R_{0}$. The average inverse-squared distance is found by averaging over $\theta$, implying equal weight is given to every source point $Q$ (uniform circular beam loss).

$$
\overline{\left(d^{-2}\right)}=\frac{1}{2 \pi} \int_{0}^{2 \pi} d^{-2} d \theta=\frac{1}{2 \pi} \int_{0}^{2 \pi}[a+b \cos \theta]^{-1} d \theta .
$$

This form can be found in standard tables of integrals and gives:

$$
\left(a^{-2}\right)=\frac{1}{2 \pi}\left\{\frac{2}{\sqrt{a^{2}-b^{2}}} \arctan \left[\frac{\sqrt{a^{2}-b^{2}} \tan (\theta / 2)}{a+b}\right]_{0}^{2 \pi}\right\}
$$

In general, the angle given by the arctan is multiple-valued, and one must carefully observe the quadrant corresponding to the integration limits. The lower limit clearly gives zero because $\tan (\theta / 2)=0$ when $\theta=0$. At the upper limit, $\theta=2 \pi$, we again find zero for the argument of the arctan. As the result of integration must be non-zero, the only sensible value for the arctan is $\pi$. That is, $\theta / 2$ has progressed continuously from 0 tbrough $\pi / 2$ to $\pi$ as the circle is completed, forcing the angle given by the arctan to take on values covering the same range. (This becomes self-evident if one evaluates the integral with $b=0$.) * The result is

$$
\left(a^{-2}\right)=\frac{1}{2 \pi} \frac{2 \pi}{\sqrt{a^{2}-b^{2}}}=\left[b^{2}-b^{2}\right]^{-1 / 2}
$$

To evaluate, we expand:

$$
\left[a^{2}-b^{2}\right]=\mathbb{R}_{0}^{4}+2 \mathbb{R}_{0}^{2} \mathbb{R}^{2}+\mathbb{R}^{4}-4 \mathbb{R}^{2} \mathbb{R}^{2}
$$




$$
=R_{0}^{4}-2 R_{0}^{2} R^{2}+R^{4}=\left[R_{0}^{2}-R^{2}\right]^{2}
$$

Taking the positive root gives the desired result:

$$
\left(\mathrm{d}^{-2}\right)=\left[\mathrm{R}_{\delta}^{2}-\mathrm{R}^{2}\right]^{-1}
$$

for the average inverse-square distance from any point on the median plane, $P$. to every point on the circle.

For points at a vertical distance, $\mathrm{Z}$, above or below the median plane, the average inverse-square distance can be found by a generalization of $a$ in the preceeding rerivation: $a=R_{z}+R_{0}^{Z}+Z^{2}$ in equation (I-1). Then, using equation $(I-4), \overline{\mathrm{d}^{-2}}$ becomes:

$$
\left(\mathrm{d}^{-2}\right)=\left[\left(\mathrm{R}^{2}-\mathrm{R}_{0}^{2}\right)+2 \mathrm{z}^{2}\left(\mathrm{R}^{2}+\mathrm{R}_{0}^{2}\right)+\mathrm{z}^{4}\right]^{-1 / 2}
$$




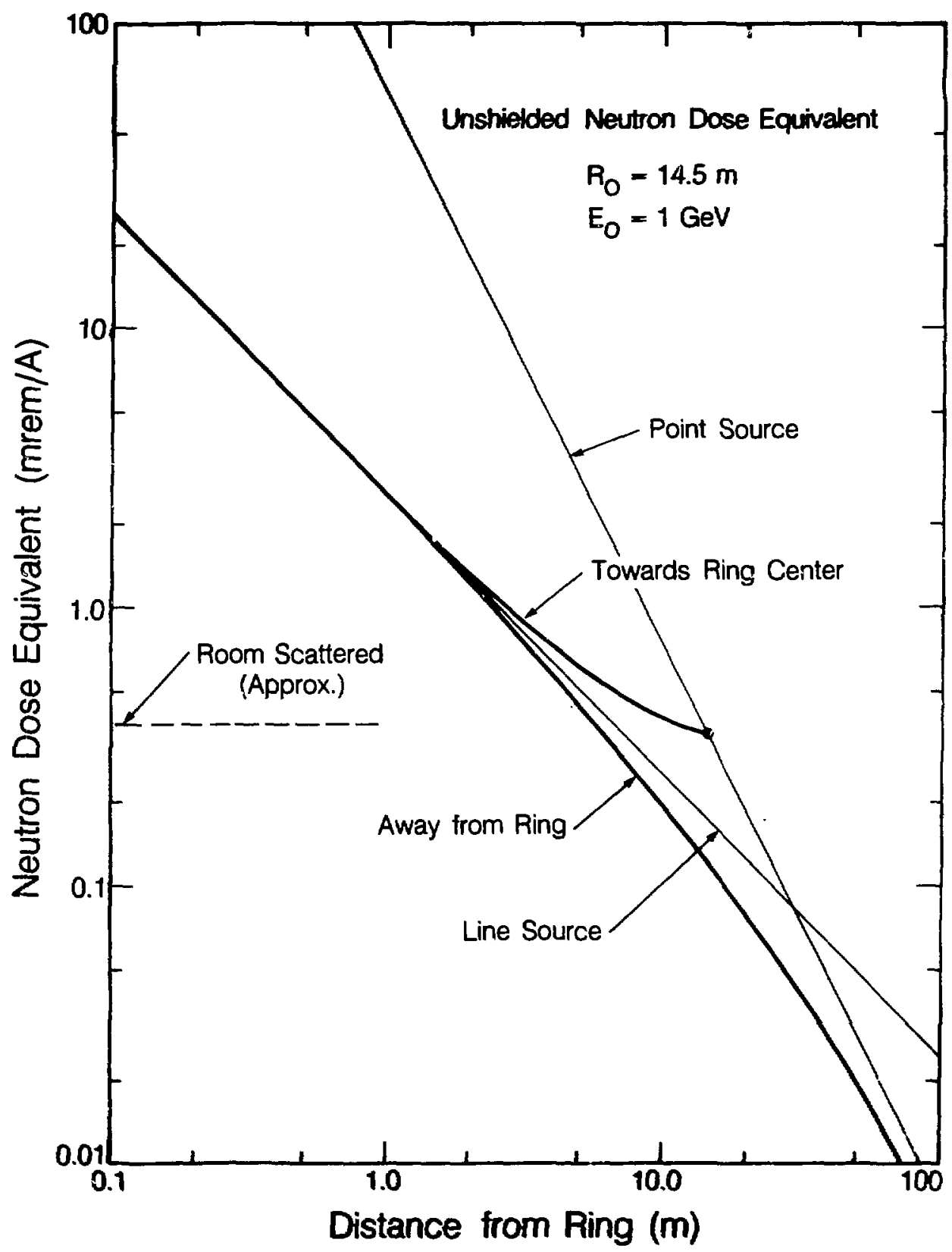

Xet 851.9319

Fig. 1 


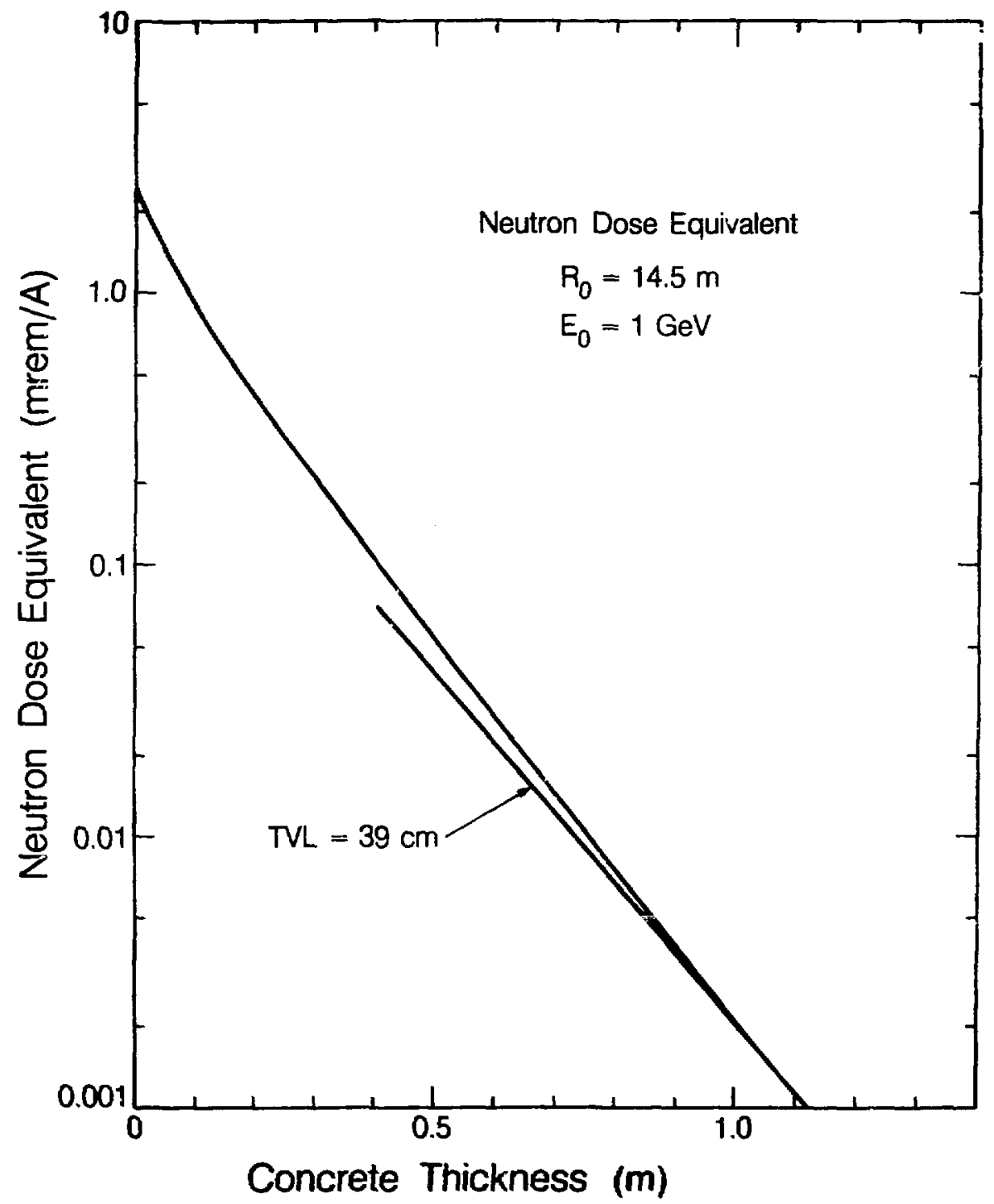

XBL. $854-9310$

Fiv. 2 


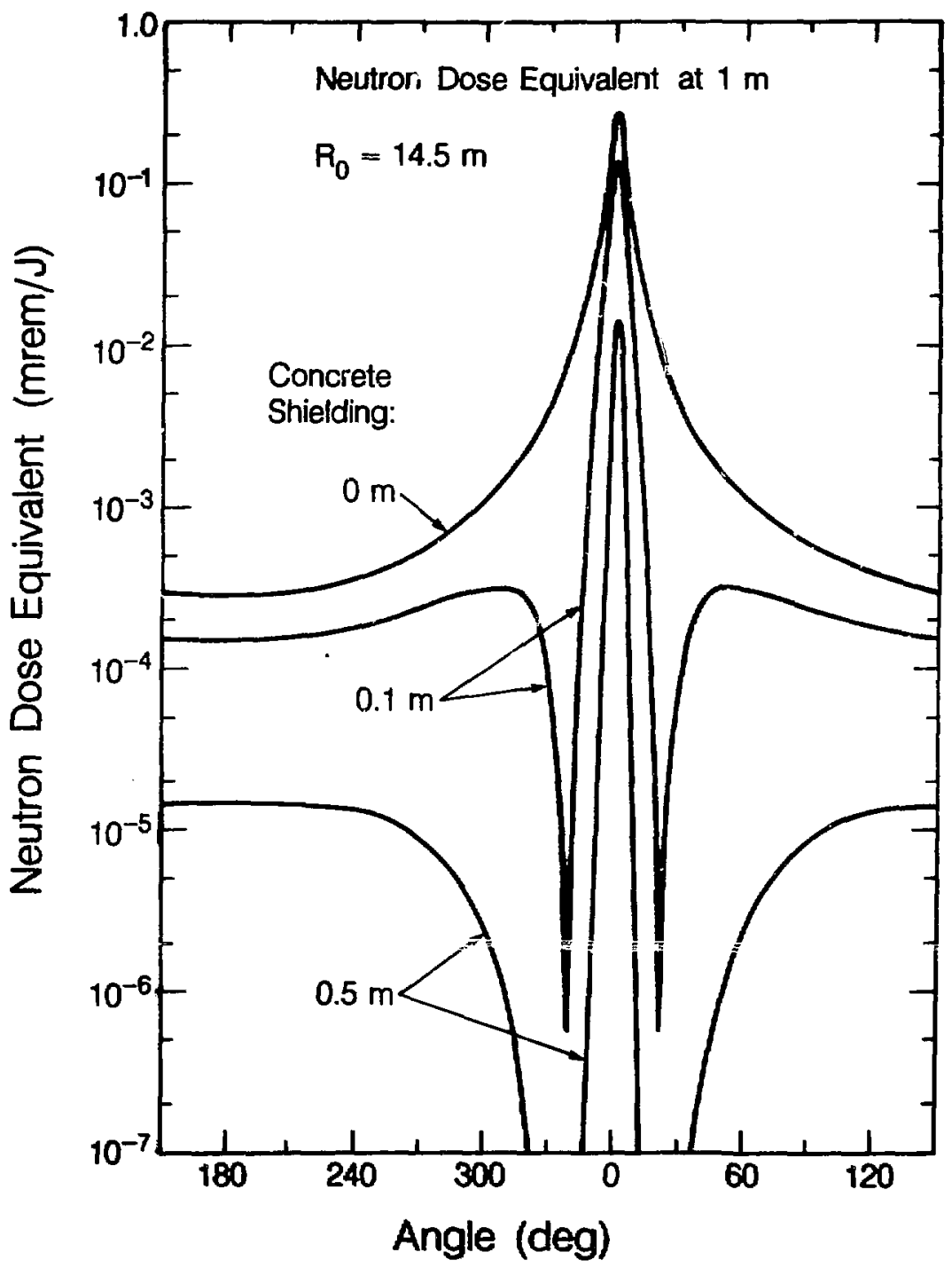

XeL 854.9311

Fig. 3 


\title{
Neutron Dose Equivalent at Electron Storage Rings
}

\author{
Milliam $P$. Swanson \\ Lawrence Berkeley Laboratory \\ University of California \\ Berkeley, California 94720
}

\begin{abstract}
Simple assumptions are used to predict the average dose equivalent from giant-resonance neutrons near a beam of circulating electrons. The methodology is derived assuming uniform beam loss around a circular ring and numerical results are given for a propos $A$ set of storage ring parameters. Comparison is made to the two smiting cases of a point source and an infinite line source of nhotoneutrons. The dose equivalent at $1 \mathrm{~m}$ from the ring is calculated as a function of concrete shielding thickness and uncertainties are discussed. By simple scaling, the method can be applied to any electron storage ring or circular accelerator, or, with suitable modification of the source term, to any device that approximates an isotropic ring source.
\end{abstract}

\section{DISCLAIMER}

\begin{abstract}
This report was prepared as an account of work sponsored by an agency of the United States
Government. Neither the United Stztes Government nor any agency thereof, nor any of employees, makes any warranty, express or implied, nor any agency thereof, nor any of their bility for the accuracy, completeness, or usefulnes, or assumes any legal liability or responsiprocess dischosed. or represents that its use would of any information, apparatus, product, or ence herein to any specilic commercial product process or manufacturer, or otherwise does not necessurily cocess, or service by Irede name, Irademark. mendation. or favoring by the United Slates Goversitute or imply its endorsement, recomand opinions of authors expresied herein do not necercarily any azency thereof. The views United States Gowemment or any agency thereof.
\end{abstract}


This report was done with support from the Department of Encroy. Any conctusions or opinions expressed in this report represent solely those of the author(s) and nox necestarily thos sf The Rezents of the Univernity of Catifornia, the Luwrenoe Berteiky Labortory or the Department of Enerty.

Reference to a company or product mame does not imply approval of recommendation of the produca by the University of California or the U.S. Department of Enercy ta the cxclusion of others that may be suitable. 